\title{
Consumer responses to a future UK food system
}

Laura O'Keefe, Carly McLachlan, Clair Gough, Sarah Mander and Alice Bows-Larkin

Tyndall Centre for Climate Change Research, University of Manchester, Manchester, UK

\section{British Food Journal}

Vol.118, No.2, 2016

DOI: 10.1108/BFJ-01-2015-0047

This paper should be citied as: Laura O'Keefe , Carly McLachlan , Clair Gough , Sarah Mander , Alice Bows-Larkin , (2016) "Consumer responses to a future UK food system", British Food Journal, Vol. 118 Iss: 2, pp.412-428

Link to published paper: www.emeraldinsight.com/doi/full/10.1108/BFJ-01-2015-0047

\begin{abstract}
Purpose -The purpose of this paper is to describe research exploring consumer responses to potential changes in food-related practices to mitigate and adapt to climate change.

Design/methodology/approach - Six focus groups explored consumer responses to measures intended to mitigate the emissions from, and adapt to the impacts of climate change. These included: meat reduction, greater reliance on seasonal British food, meal replacement tablets, laboratory grown meat, communal eating houses, genetically modified food and food waste. Practice theory provided the lens to interpret the changes to meanings, competences and materials associated with food consumption.

Findings - Changes that could be assimilated within existing competencies were viewed more positively, with lack of competence a key barrier to accommodating change. At present, climate change and sustainability do not influence purchasing decisions. Policy measures delivering multiple benefits ("win-wins"), of which environmental performance may be one, stand an improved chance of establishing more sustainable practices than those focusing exclusively on environmental drivers.

Originality/value - Awareness of the role of sustainable food systems in the context of anthropogenic climate change is growing. Whilst scientific and technological research explores methods for reducing emissions and building resilience in food supply chains to changes in climate, there is comparatively little study of how consumers perceive these proposed "solutions". This research provides a comprehensive overview of consumer responses to potential changes in eating practices related to climate change mitigation and adaptation and is of value to policy makers, academics and practitioners across the food supply chain.
\end{abstract}

Keywords - Mitigation, Adaptation, Consumers, Food, Climate change, Meat reduction, Eating practices 


\section{Introduction}

What constitutes a 'low-carbon' or 'sustainable' diet is both greatly contested and challenging to define (Carlsson-Kanyama 1998; Casimir and Dutilh 2003). With an increasing global population, growing demand for food and vulnerability to the 'dangerous' impacts of climate change, both the nature and geography of food production will change and adapting to these changes will be experienced across the entire food supply chain. Whilst scientific and technological research increasingly explores potential methods for both reducing emissions from food and building resilience in food supply chains to changes in climate (Garnett 2008; Ambler-Edwards et al. 2009; Soil Association 2009; DEFRA 2010; Foresight 2011; Bows-Larkin et al. 2014; Roder et al. 2014; Wood et al. 2014) there has been comparatively little study of how consumers may perceive and respond to proposed 'solutions'.

This paper describes empirical research using a focus group approach to explore consumer responses to the UK food system and the potential changes in their food-related practices that could feature in a future altered by climate change. This research was conducted as part of a larger integrated project which explored climate change adaptation and mitigation in the UK food system and developed five Scenarios for the UK food system up to 2050 (Bows et al. 2012; Mander et al. 2013; Bows-Larkin et al. 2014; Roder et al. 2014; Wood et al. 2014). The paper begins by introducing the focus group discussion topics, the remainder of the paper aimed to gain a better understanding of how potential changes might be received by consumers and to identify the policy implications associated with moving towards a food system that is more robust to climate change. The paper concludes with how the focus group results relate to future food practices. 


\section{Rationale for discussion topics}

It has been suggested that consumers in wealthy nations will have to 'reduce their overall levels of consumption' if the target of $80 \%$ reduction in greenhouse gas emissions by 2050 , set out in the Climate Change Act, is to be achieved (Buenstorf and Cordes, 2008; Soil Association, 2009). Moreover, some argue that even such a progressive target is inadequate for a reasonable probability of avoiding the $2^{\circ} \mathrm{C}$ threshold between 'acceptable' and 'dangerous' climate change (Anderson and Bows, 2011). Considering this, focus group discussions were framed around six key topics taken from Scenario narratives which could be described as measures potentially contributing to either climate change adaptation (defined as the "adjustment in natural or human system to a new or changing environment") or mitigation (defined as "an anthropogenic intervention to reduce the sources or enhance the sinks of greenhouse gases") (IPCC, 2007). Mitigation measures included eating less meat and reducing waste (in terms of both food and economies of scale through communal 'eating houses'). Other measures had both mitigation and adaptation potential including: growing meat in a laboratory, increased consumption of Genetically Modified (GM) foods, eating only British seasonal foods and the consumption of pills as a replacement for traditional food. Further rationale for their inclusion in the Scenarios is explained below.

\section{Eating Less Meat}

Research suggests that reducing meat consumption is an unpopular way of reducing the environmental impact of diets (Owen et al. 2007; Tobler et al. 2011) but with the average British adult consuming $79.1 \mathrm{~kg}$ of meat a year (National Diet and Nutrition Survey 2012) compared to a global average of $38 \mathrm{~kg}$ (FAO 2009) it is clear something needs done. A global transition to a low meat/vegetarian diet could have a dramatic impact on land use, resulting 
in substantial reductions in greenhouse gases (Williams et al. 2006; Stehfest et al. 2009; Garnett 2011; Berners-Lee et al. 2012; de Boer et al. 2013; Hoolohan et al. 2013). This key climate change mitigation measure is the focus of grassroots campaigns such as 'Meat free Monday' (Meat Free Monday Campaign 2013) and other scenarios aiming to reduce food system emissions (Audsley et al. 2009). Meat production requires more water, land and energy in absolute terms than crops and accounts for $18 \%$ of global greenhouse gas emissions (FAO 2009). With global cattle numbers predicted to rise significantly by 2050 (Speedy 2003;FAO 2006), resource use is likely to increase unless drastic changes in diet are made. It is unclear as to how willing consumers may be in reducing their meat consumption, though a YouGov poll found a quarter of those surveyed had reportedly cut back on their meat consumption in the past year however the motivations behind this reduction were not explored (Eating Better 2013). Research found that consumers tend to underestimate the environmental impact of meat production and would therefore not necessarily identify reducing meat consumption as a significant way of making their diet more 'climate-friendly' (Tobler et al. 2011; Hartikainen et al. 2014; Vanhonacker et al. 2013).

\section{British Seasonal Food}

Increased consumption of indigenous seasonal foods may occur as a means of adaptation to climate change when imported produce is unavailable or as a mitigation measure to reduce transport $\mathrm{CO}_{2}$. In the UK, $40 \%$ of food is imported (DEFRA 2011) with the largest proportion of emissions arising from transportation and refrigeration (Jones 2002; Foster et al. 2006). When non-seasonal food is grown in the UK, emissions result from required additional inputs such as heat (Webb et al. 2013). The consumption of seasonal local products could lower overall emissions through reduced inputs (compared to non-seasonal production) and 
reduced transportation and refrigeration related emissions (Cholette 2008). Research has indicated the consumption of local seasonal food is perceived by consumers to be environmentally friendly (Tobler et al. 2011) and superior in terms of taste and freshness (Chambers et al. 2007).

\section{Genetically Modified Food}

A technical response to addressing both climate change mitigation and adaptation is through genetic modification of crops, to enable production with reduced inputs or to minimise vulnerability to the impacts of climate change (The Royal Society 2009; Ronald 2011); the benefits of Genetically Modified (GM) are, however, contested (Friends of the Earth 2010). Extensive research has been published on public understanding and perceptions of Genetically Modified (GM) foods, key issues for consumers include: 'unnaturalness', unknown risks, lack of perceived benefits, 'avoidability', health implications, the motivations of those promoting the technology and a sense fatalism over the expansion of GM food (Grove-White et al. 1997; Nelson 2001; Shaw 2002; Pidgeon et al. 2005; Tobler et al. 2011).

\section{Laboratory Grown Meat}

In vitro or laboratory grown meat is constructed using tissue-engineering techniques and has been proposed as a lower environmental impact alternative, allowing for meat production where climate impacts could make it difficult to rear livestock (Thorton 2010). Tuomisto and Teixeira de Mattos (2011) calculated that production of laboratory grown meat uses $35-60 \%$ less energy, has $80-95 \%$ lower GHG emissions and $98 \%$ lower land use than conventional meat production. Producing meat in this way has the potential to make 
meat healthier by improving the saturated/polyunsaturated fat ratio, reducing food borne diseases by increased monitoring and have land use benefits gained from releasing land from meat/ animal feed production (Edelman et al. 2005). De Barcellos et al (2010) found that consumers were highly critical of 'excessive intervention' in meat production, suggesting that, technical challenges aside, its introduction may not be straightforward.

\section{Communal Eating Houses}

Communal 'eating houses', were introduced in the Scenarios as an alternative to dining at home, with the aim of reducing waste by cooking on a large scale. It is estimated that $20 \%$ of food bought for consumption ends up as waste in British homes (WRAP 2011). Exploring the social processes underlying food waste, Evans (2012) stresses the complex factors which result in 'usable' food being thrown away, encompassing both social (e.g. satisfying the preferences of different family members) and material (e.g. the role of fridges/freezers) dimensions.

\section{Meal Replacement Tablets}

'Meal replacement tablets' were included in the Scenarios to reflect restrictions in the availability of certain products and as a way of reducing emissions whilst maintaining recommended nutrition levels of a 'healthy' diet.

\section{Material and methods}

The empirical research described in this paper explores consumer responses to potential changes to their diet and food related practices that might feature in a future food system altered by climate change. Six focus groups with a total of 40 participants were held at The 
University of Manchester (UK) in late 2011 and early 2012. A focus group ${ }^{1}$ approach allowed the opportunity to gauge responses to the suggested changes and offered the opportunity to explore participants' presentation and interpretation of their everyday food related practices in response to the discussion topics (Morgan 1993;Therwell 1999;Krueger and Casey 2000;Stewart et al. 2007).

\section{Recruitment}

Achieving UK climate change targets require a shift in policy; support from the public is seen an essential step in achieving these targets so early engagement is critical (Lorenzoni et al. 2007). It was deemed important to understand responses to the proposed 'solutions' identified in this paper and as such the general public were identified to recruit. A mail shot was sent to households ( $n=1400$ ) within the Greater Manchester area inviting them to contact the research team to express an interest in participating. 10 participants were invited to each focus group, commensurate with standard practice (Gibbs 1997; Stewart et al. 2007) and aiming for a target group size of 6 to 8 people (Krueger and Casey 2000); in total, 21 males and 19 females took part. A cash incentive and travel expenses were offered to each participant. Stewart (2007) found that the ability to create rapport and maximise discussions within the focus group was heavily influenced by gender composition. Taking this and previous experience into consideration, groups were split by gender, with the aim of encouraging an open atmosphere conducive for information sharing (Calder 1977; Morgan 1993).

\footnotetext{
${ }^{1}$ Focus groups, where a group of people are asked in an interactive setting about their attitudes towards a particular topic and have been used successfully within other studies examining consumption (Barr et al. 2011a; Chambers et al. 2007; Murray and Vickers 2009; Barr et al. 2011b; Bray et al. 2011).
} 


\section{Procedure}

In designing the topic guide, we sought to facilitate discussions based on key topics taken from the Scenarios, whilst encouraging participants to discuss any issue raised in relation to shopping, food preparation and eating. Each focus group lasted approximately 2 hours and was moderated by the same researcher to ensure consistency. The topic guide was divided into two; beginning with 'warm-up' discussions based on current shopping influences and sustainability before focusing on discussion topics which were introduced to participants in the following order: eating less meat, eating more seasonal British food, meal replacement tablets, laboratory grown meat and communal eating houses. Discussion topics were introduced in the context of how their diets and behaviour might change in response to the climate mitigation and adaptation responses.

\section{Analysis}

Discussion was audio taped with each session transcribed verbatim then verified by the researchers. The transcripts were entered into qualitative data analysis software package Atlas.ti (Muhr 1998). Transcripts were coded iteratively using the topic guide for preset codes and then developing new codes as they emerged. Although a specific theoretical framework was not adopted a priori, in analysing the data, it became clear that participants' discussions related to elements of practice theory. Randles and Warde (2006) state "that the principle implication of a theory of practice is that sources of changed behaviour lie in the process whereby practices themselves are reproduced or altered", thus making it particularly relevant to this research. 


\section{Applying a practice lens during analysis}

Practice theory emerged in the 1970s and has been described as "a body of work about the work of the body" (Postill, 2010). There are many variants of practice theory put forward by theorists such as Dreyfus, Bourdieu, Giddens, Lyotard and deCerteau (Schatzki, 2001) however this research will however draw upon more contemporary theorists in its analysis. A practices approach, by definition, considers the 'doing' of everyday life as the focus of its analysis, moving away from an emphasis on attitudes, values and processes of 'decisionmaking' (Schatzki 2002; Shove and Warde 2002; Hargreaves 2011) to specific behaviours and patterns of consumption seen as being contained or embedded within certain social practices (Hargreaves, 2011). In his study of environment-related behaviour, Hargreaves (2011) demonstrates how insights from practice literature offer a wider and more comprehensive understanding of both the existing 'unsustainable' practices and the potential policy interventions that could be adopted in order to establish more 'sustainable' practices. Applying a practice lens to the present analysis aims to develop this insight further and explore specific issues relating future food-related practices, while recognising the complexities associated with 'eating' as practice (Warde, 2013).

The core elements of practice are conceptualised by Shove and Pantzar (2005) as 'meanings', 'competences' and 'material'. Meanings refer to images and symbols which, in the case of food, could include healthiness, localness, choice etc, and which are strongly influenced by many cultural, individual and family factors (Daniels et al. 2012). Competences refer to skills and procedures which could include: cooking techniques; knowledge of recipes, ingredients and storage etc. Finally, material refers to physical 
infrastructure and technologies such as food production, retail outlets, kitchen technology, the locations of eating etc. These elements are used in the analysis of this research project.

\section{Results}

During 'warm-up' discussions participants were asked about current shopping influences. The dominant issues across all groups were food prices and affordability, sustainability issues were not mentioned unless prompted by the researcher. Participants were asked what the term 'sustainability' meant to them, the only issue common to all groups was food miles. It should be noted that none of the groups mentioned 'climate change' directly in this prompted discussion on sustainability.

The remainder of this section will now present results describing participant responses to the climate change mitigation and adaptation measures featured in the Scenarios.

\section{Eating less meat}

Respondents were first asked how they viewed a $20 \%$ reduction in meat consumption and whether it was achievable. The current cost of food and economic recession featured heavily, respondents spoke of changes they were already making in terms of purchasing meat to make their budget stretch further: "When I was really running out of money, I was thinking why am I spending money on chicken? I can just have a vegetable curry". In the context of stretched budgets, quality remained important, as participants expressed a willingness to reduce spending in other areas of their food shopping budget to maintain the standard of meat products. Various other meanings were also drawn on: animal welfare issues were often mentioned alongside price and quality in discussions around respondents' 
current reasons for reducing meat consumption: "I've stopped buying meat because of the price, but also because of the way that it gets from being alive to on your plate. I'm not sure I'm particularly comfortable with that." Only a minority discussed the emissions implications (i.e. environmental impact) of eating meat: "Meat has the highest carbon emissions by such, you know, a high level. And meat rather than fish. We eat lots of meat. Fish are unsustainably sourced, but it doesn't produce lots of carbon emissions in its extraction, basically". The majority of participants stated they were comfortable with the suggestion of a $20 \%$ reduction in meat consumption (interpreted as an incremental change to their current diet) and which could be accommodated within their existing culinary competencies: "I wouldn't find it a huge issue because I've already gone through that eating meat almost every night to a couple of times a week. It's not really that hard." Respondents tended to quickly move to how they could achieve such changes, whether through consuming more meat substitutes, vegetarian meals or reducing the amount of meat in existing dishes: "Out of interest, would you do that by having four meat meals a week instead of five, or would you have the same five meat meals but with $20 \%$ less meat?". Respondents were generally willing to consider a $20 \%$ reduction, primarily due to: the winwin nature of the change (cost and environment), the context of stretched budgets and interpreting it as an incremental change that could be adopted within current competencies.

When asked about a 70\% reduction in meat, this was considered too drastic a shift from current practices, leading participants to suggest clearer dietary guidance from government sources would be needed to adopt such changes. Predicted reluctance by other family members was perceived as one of the biggest barriers to this $70 \%$ reduction, introducing 
additional meanings associated with meat consumption: "They'd say, "Mum, are you poor? Where is our meat?" because they're too used to it." Furthermore, parents reported they would be happy to reduce meat consumption for themselves but not for their children, due to their perceptions of the role of meat in satisfying nutritional needs: "I prefer them to eat meat cause when they do they're more full and I know they're getting a proper meal inside them."

Females considered men in their families would find both a $20 \%$ and $70 \%$ reduction in meat consumption problematic: "I'd be happy to eat less meat but my husband likes to have meat on every dinner." Males, however, expressed similar levels of personal willingness to reduce meat consumption. A $70 \%$ meat reduction was frequently referred to as a 'vegetarian' diet by participants. Participants discussed barriers to making the $70 \%$ reduction which included the need to develop new competences, expressed as a lack of awareness of reduced-meat recipes and the perceived effort involved in making vegetarian meals. Participants spoke of having grown up with traditional 'meat and two veg' meals and felt unsure of how to incorporate satisfying meat-free meals into their diet concerned that reducing meat to such an extent would result in boring and repetitive meal times: "So if someone who eats a lot of meat like myself who doesn't eat particularly a lot of veg, what would you eat then?" Respondents stressed the need to be given positive messages on what could be eaten rather than simply being told not to eat meat: "If a campaign was like don't eat meat twice a week, I think a lot of people would go, "So I starve for two days a week?" You have to give people an alternative." 
Feeding other family members, ensuring variety in terms of health and interest plus uncertainty over what to cook given many participants were traditionally so used to eating meat, were all discussed as potential barriers to more 'drastic' reductions. Participants also discussed: "I don't know if it's a black culture and that's just what we're used to, but in Jamaica and India, everything just involves meat... $70 \%$ is too big of a jump for me."

\section{British Seasonal Foods}

Participants questioned what would be available when asked how they would respond to only being able to eat British Seasonal foods. Knowledge of seasonal availability varied with consideration of the 'seasonality' of products an alien idea for some: "Cadbury's cream eggs, they're seasonal...that's the only seasonal food I know. And it sounds stupid, it really does, it genuinely is". Lack of familiarity with seasonality was seen by participants as the result of current year-round availability of the majority of fruit and vegetables and the level of choice with which they were accustomed to at British supermarkets and felt that reducing that choice would be difficult: "I supposed you'd feel a bit deprived wouldn't you in some respects."

A reduction in variety, either by choosing to eat more seasonally (mitigation) or products being unavailable (adaptation), differs markedly to current expectations. Participants felt any voluntary change was unlikely to happen and a reduction in choice would not be well received. Such a change was seen as going 'backwards': "That's one of the things; we love choice of whatever it is, be it leisure activities, be it food, drink. We're spoilt for choice. 
Probably we have too many choices. So to try and sort of backtrack on that would be an incredibly difficult thing."

Discussions focused on voluntary consumption of more seasonal foods. When prompted on the possibility of foods not being available or the price dramatically increasing, there was a desire to protect current levels of choice and an expectation that this could and would be achieved through various technical measures (e.g. glass houses in the UK): "You know all the glasshouses for the tomatoes at the moment I suppose they could do that for oranges and melons and things and bananas...you'd have to put Britain under glasshouse I think". The need to develop new competences to cope with this change to the material of food consumption came to the fore; the majority of participants reported they would need more information on the foods they would have access to, and the recipes they could cook with the available products, in order to feel confident and comfortable with such a change: "I'd be hard pushed to know what was British and in season at any one point". Mirroring concerns about reducing meat in diets, participants argued building wider enthusiasm for voluntarily changes, or enabling them to cope with changes would depend on knowledge of not only the types of products available but what satisfying meals could be provided using those products: "You couldn't just go in and sort of make the decisions there and then or whatever. You'd kind of have to be thinking about - thinking ahead a little bit more." Supermarkets were seen as central, with calls for them to provide information on tasty and varied recipes, prominent placement and promotion (including price) of seasonal goods. Groups talked about encouraging consumers to choose more seasonal products, with the 
assumption more exotic products would nevertheless remain available. A reduction in choice was seen as going 'backwards' and against 'progress'.

\section{Lab grown meat}

The concept of artificially growing meat was couched in wider sustainability issues that had arisen during the previous prompted topics and was framed within the context of the 'need' for producers to maintain at least current levels of quality and choice and notions of 'progress' in terms of food production: "We can only go forwards. And if people expect all these exotic foods all year round and people expect meat there has to be another way of providing it..." Participants in all groups discussed the science behind making such a product, with many worrying that based on previous food scares that given there is no evidence to ensure its safety there may be problems in the future: "You'd have to put your trust in science every time you grilled a burger which is a bit worrying you don't like to do it do you but I think eventually I would."

Despite several participants having seen a news story on artificially grown meat the groups had many questions surrounding the actual product, the taste was an obvious issue but participants were concerned with what it would actually look like when it came to the stage of purchasing: "Because aesthetics of food is important as well, isn't it?". Despite the potential benefits of lab meat, the importance of transparent labelling and choice was also discussed. There was a need for consumers to be able to compare products 'side by side', with a sense that visual comparison would be important for shoppers (and was already part of existing meat selection processes). 
Although participants expected a technological development to be costly, there was a general consensus that lab meat would have to be cheaper than conventional meat to encourage consumers to switch, for example if participants could purchase an improved 'cut' of meat at a lower price: "They're not going to be growing the rough end of the meat trade, they're going to be growing the better end. So you know, if you can get the better end of the meat for the price of the rough end, great".

Overall the majority of respondents were open to the concept of lab meat with the main advantage identified by both vegetarian and meat-eating participants was the availability of meat without killing an animal: "Well nothing's dead because of it and we still get to eat meat so I think it's the best of both worlds. I don't mind about the Frankenstein thing at all." Previous discussions highlighted the importance of meat in participant's diet, however discussions around growing meat specifically for food highlighted the importance of animal welfare to many participants: "I'm all for scientific advances. If it tasted the same as normal meat as well, I'd prefer to eat something that's been grown specially to be eaten than something that's had to live a life just to be eaten".

Participants discussed and questioned the nutritional and health implications of consumption, however came to the conclusion 'scientists' could produce a product which was not only 'purer' than conventional meat but could contain added vitamins and minerals: "They wouldn't grow any rubbish would they?" Participants raised concerns about "growth hormones' in meat produced today. Across the groups, the idea that lab meat could perhaps offer a higher standard of safety and quality was discussed unprompted: "And look 
at the bovine diseases...if labs were guaranteeing sort of $100 \%$ safety with these things, I think people would probably trust a laboratory more".

A sense of 'progress' underpinned much of the positive discussion around lab meat. In the context of the industrial nature of current food production, it was seen as perhaps not being such a significant change. Historical technological developments, such as microwave meals, were considered by some to be analogous: "Microwave meals. If you said to people, "At a certain point, you will get a tray of food that's been processed in whatever weird and wonderful way and you'd bang it in a microwave and, a minute later, you'll have a meal," if you had said that to grandparents, they would have been like, "Absolutely no way that's going to happen."

\section{GM food}

Participants were on the whole unsure of the extent to which their current shopping basket would contain GM foods and had concerns: "For me the product would have to be on the market for a certain number of years... just always worry there [is] going to be some payback down the line, you know, they'll come up with such and such in the Daily Mail about whatever."

Participants saw an important role for information provision, arguing there should be a much higher level of understanding within the general public (including themselves) if more GM food products were included on supermarket shelves and to enable individuals to make the choice whether or not to consume them. As with lab meat, participants discussed the issue of some consumers having little or no choice but to consume certain products if they 
are the cheapest on offer: "GM food strikes a chord, we don't really know too much about it, but we know it's not particularly good...But if you can't afford anything else and you've got a family to feed, you'll go for it."

The meanings associated with GM foods were more negative than lab meat. Whilst respondents could see potential benefits of the technology, they linked their negative associations with GM food to past media coverage, highlighting the importance of media framings to the introduction of other 'new technologies'.

\section{Meal Replacement Tablets}

Participants spoke enthusiastically about the cultural and social importance of food and the substantial amount of time they spent shopping for, preparing and eating food: "I like cooking and I like the smell of food and like the preparing it and the sitting down at the table and stuff like that it's not just actually eating what you're eating it's everything else that goes with it."

Meal replacement tablets were rejected by the majority of participants on the grounds of the important role food played in their lives, expressed in terms of all three elements of practice (meaning, materials and competencies). Concerns were raised over how the human body would respond to an absence of 'proper food': "That's already processed. It's not the same as fresh, wholesome food, freshly cooked. It's not the same." 
Those who spoke positively about meal replacement tablets drew on a number of potential benefits including saving time, managing nutrition and over-eating and feeding a growing population, students in particular saw a benefit: "You don't have to think about what you're going to have. You don't have to do a big shop, which is a right pain if you don't have a car. Yeah, that would just be really simple and easy for me." A similarity between meal replacement tablets and the materials of some current weight management programmes was noted. Although they were seen as being 'futuristic' and hi-tech, meal replacements tablets were not associated with positive images of 'progress': "You meet with friends, you go out for a meal, you cook a meal, you sit down and you talk about your day, don't you? You're not going to sit there over a tablet, are you, saying, "Oh, this is what I've done today, darling, " you know, gulp, it's over, let's move on from that." Participants with families also had concerns about their family of meal replacement tablets were introduced: "With us both working full-time it is probably like that half an hour is the only time we actually spend really all four of us together. So to take that away god it would be horrible it would that's like our time".

\section{Eating Houses}

In the context of the central role that shopping, cooking and eating takes in everyday lives, this change was viewed very negatively by each of the groups. Despite a very open-ended introduction of this idea to the groups, with no explanation of the level of choice or eating environment, it was immediately interpreted very negatively as being impractical and inconvenient. The suggestion of an 'eating house' provoked images of large military-style canteens serving "slop": "This sounds a bit sort of Soviet, you know, old-style ... It sounds really horrific to me." Participants were quick to list a range of unprompted concerns 
including: increased waste, lack of choice (particularly for children), unhealthy foods, food safety, special dietary requirements, quality and taste of the food, aggravating social problems. Eating houses were perceived to limit choice and were not seen as analogous with restaurants or other food outlets: "It's limiting choice again like you've got a set menu I presume or it's like when you eat at school or at work or whatever".

The majority of participants disagreed with the rationale behind the idea and did not mention any potential personal benefit, such as reducing the need for shopping, cooking or washing up, for example; respondents had to be strongly encouraged to identify any potential benefits at all. Only one participant across all six groups proactively suggested that it might be a good way to meet your neighbours and become more sociable. In stark contrast to the technological options of lab meat and GM food that were seen as a way of maintaining and developing current food choices, eating houses were considered to represent a return to less affluent and abundant times and this framed respondents' sense of the undesirable and improbable prospect of their implementation: "Yeah, like let's go back to the depression." Again, it is evident here that, to be widely accepted, it is important that changes in diet are not considered to be incongruent with notions of 'progress'.

\section{Discussion}

By applying a practice lens during the analysis stage of the research we were able to widen the focus from individual decision making to consideration of the broader constituent parts of food consumption. Results are now discussed in the context of the three core elements of 
practice: meaning, material and competencies, highlighting opportunities for policy intervention that such a framing opens up.

\section{Meanings}

Meanings associated with food and eating practices were widely discussed by participants throughout the focus group as they assessed the acceptability and likelihood of the proposed changes.

The role of meat in diets proved a particularly emotive topic compared with the others; meanings that surfaced during the discussions relating to the social status of eating meat, family expectations and animal welfare issues. This compliments research by Holm and Mohl (2000) who found that discussions around meat carried more emotion than any other food. Animal welfare issues were introduced during discussions relating to lab meat, during which positive images of 'science', 'progress', 'safety' and 'purity' were contrasted with negative images of current 'industrial' approaches to farming livestock. A sense of technological optimism pervaded these discussions as lab meat was heralded as an innovation allowing for better 'cuts' of meat at a lower cost.

Choice and price were dominant themes across the groups and topics. Choice was presented by participants as a central and positive meaning of current food practices and led respondents to expect resistance to any perceived limiting of choice. The level of choice currently available was framed very positively and presented as 'progress', while any measures associated with restricting choice were described as 'backward' or negative. There was a clear assumption that retailers could and would maintain current levels of choice and 
any changes proposed were interpreted as being voluntary actions (compared to items simply not being available). This dominance of choice as a key meaning was further evidenced in their confidence that climate adaptation issues (e.g. lack of availability of certain fruit and vegetables from overseas) would be likely to be overcome by technical solutions, such as heated greenhouses in the UK for example. The importance of choice was also evident in respondents' desire for hi-tech options (GM and lab meat) to be clearly labelled and 'avoidable' for the consumer. For the vast majority of participants, choice was deemed an immutable part of the food system.

Rising food prices were seen to be disrupting current food practices, offering policy makers the potential for 'win-wins' on cost and sustainability. When they could identify multiple benefits, participants viewed potential changes to diet and food related practices more favourably. Such win-wins related to changes where additional positive meanings were associated such as: health, welfare and quality. Participants did not draw on broader meanings of environmental impact or sustainability when discussing their current shopping influences and pressures. The absence of meanings related to sustainability when participants discussed their current food habits suggests that presenting change exclusively in terms of environmental benefits may have limited effect.

\section{Material}

For those changes that clearly altered the material of food consumption (e.g. lab meat, eating houses, meal replacement tablets), the extent to which they were seen to support or undermine current meanings was central to how they were assessed by respondents. Changes in material that maintained or enhanced choice were generally viewed positively. 
Participants identified that supermarkets and food producers could reduce the environmental impact of products, through changing the material (i.e. technical improvement and efficiency gains) without the consumer having to alter their practices; by not altering current meanings and fitting current competencies, such changes were viewed positively.

\section{Competences}

Participants frequently discussed how to assimilate changes within their existing competences. A clear example of this related to meat consumption, where a $20 \%$ reduction was seen as being broadly compatible with existing competences. In other words, respondents could comfortably see how to produce meals that satisfied both their families' and their individual desire for choice and variety within this magnitude of change. Not only was this achievable within current competencies but it was perceived as being consistent with current budget constraints, without being a major challenge to meanings of choice and health. This is in contrast with research by Tobler et al (2011) who found participants to be unwilling to reduce their meat consumption. A 70\% reduction in meat consumption, however, was viewed more negatively because it was perceived to challenge both choice and health in addition to raising concerns about the lack of skills and know-how to deliver satisfactory meals with such a reduction in meat.

The topic of seasonality was also seen to present a test of participants' skills and their ability to utilise a 'restricted' shopping list. In the context of both the need to reduce meat consumption and potential climate change impacts on the availability of particular fruit and vegetables, participants called for supermarkets and government to assist them in 
developing new competencies in order to accommodate these changes to their eating practices. Whilst 'deficit models' are clearly of limited value in transforming patterns of consumption (Irwin and Wynne 1996), participants spoke of a desire to 'know more' if such changes were to happen, suggesting that improved provision of information and training (competence) may be a necessary (but not sufficient) condition to facilitate such change. In line with positive meanings around food and the enjoyment that participants took from eating and cooking, they called for changes to be presented positively, for example through messages about what to eat rather than negative instructions to stop eating meat. Suggested approaches included supermarkets providing vegetarian recipe cards and offering promotions on relevant ingredients in store.

\section{Insights from a practice framing}

Respondents discussed the desirability and likelihood of specific proposed changes to food consumption; the content of these discussions has been interpreted with reference to the three elements of practice: meanings, material and competences. Each of these three elements has been discussed. Dominant meanings of 'progress' and 'choice' were evident throughout discussion of the proposed changes. Respondents discussed their ability to accommodate changes within their current competencies and argued that more support and training would be needed if they were to make changes that they perceived as 'radical' i.e. a $70 \%$ reduction in meat consumption and eating only British seasonal food. The different meanings associated with specific hi-tech changes in the material of food (i.e. lab meat and GM) led to different responses to those change. In relation to GM, participants drew on existing knowledge and uncertainties that have been well documented in the media to express concern over health implications and a desire to be able to actively avoid 
GM. Lab meat, on the other hand, a new technology for many respondents and not currently in the food supply chain, was seen as having the potential to fit with existing meanings of value (i.e. rising food prices making meat too expensive for some) and health; notably, potential advantages were expressed in relation to previous food scares and a more 'scientific' approach to meat production. Whilst this response is likely to be strongly affected by media coverage as the technology develops, this, and the example of meal pills offer a good examples of the importance of understanding consumer interpretations of the meanings associated with new technologies and products and their related risks (Cope et al 2010).

\section{Conclusions}

This paper has presented results from focus groups exploring consumer responses to potential changes to eating practices related to climate change mitigation and adaptation. Using elements of practice theory to inform the analysis, the analysis shifts from a narrow emphasis on individual attitudes, towards a more comprehensive view of patterns and systems of eating - i.e. food related practices. In particular, the elements of practice: meanings, materials and competences, are explored.

Initial discussions with respondents indicated that climate change and sustainability did not feature in the current meanings associated with food or in purchasing decisions. Here it is argued that policy measures delivering multiple benefits ('win-wins'), of which environmental performance may be one, stand an improved chance of establishing more sustainable practices than those focusing exclusively on environmental drivers (e.g. health and cost). In particular, as current financial pressures disturb shopping and eating habits a window of opportunity may exist for new patterns to be established. It is important that the 
implications of any proposed changes are considered in the widest possible context of food practices. Considering proposed policies and initiatives from the perspective of changes to meaning, competence and material is argued here to offer a productive and useful starting point for policy makers. Determining how changes can be assimilated within existing competencies (e.g. cooking, preparing) and their congruence with existing meanings of food practices (e.g. progress and choice) is central. This requires a shift in policy and campaigning discourses to identify synergies that speak to all three elements of practice.

While the research presented here has been enriched by analysing the results of the focus group discussions through the broad lens of practice theory, future research to develop scenarios taking a practice approach from the start, could deliver further valuable insights into achieving more sustainable food futures.

\section{References}

Ambler-Edwards, S. , Bailey,K. , Kiff, A. , Lang, T. , Lee, R. , Marsden, T. , Simmons, D. and Tibbs, H. (2009), "Food futures: rethinking UK strategy", Chatham House Report.

Anderson, K. and Bows, A. (2011), "Beyond 'dangerous' climate change: emission scenarios for a new world", Phil. Trans. R. Soc. A , Vol. 369 No. 1934, pp. 20-44.

Audsley, E. , Brander, M. , Chatterton, J. , Murphy-Bokern, D. , Webster, C. and Williams, A. (2009), "How low can we go? An assessment of greenhouse gas emissions from teh UK food system and the scope to reduce them by 2050", WWF-UK.

Barr, S. , Gilg, A. and Shaw, G. (2011a), “'Helping people make better choices': exploring the behaviour change agenda for environmental sustainability", Applied Geography, Vol. 31 No. 2, pp. 712-720.

Barr, S. , Shaw, G. and Gilg, A. (2011b), "The policy and practice of 'sustainable lifestyles'”, Journal of Environmental Planning and Management, Vol. 54 No. 10, pp. 1331-1350.

Berners-Lee, M. , Hoolohan, C. , Cammack, H. and Hewitt, C.N. (2012), "The relative greenhouse gas impacts of realistic dietary choices", Energy Policy, Vol. 43, pp. 184-190

Bows, A. , Dawkins, E. , Gough, C. , Mander, S. , McLachlan, C. , Roder, M. , Thom, L. , Thornley, P. and Wood, R. (2012), What's Cooking? Adaptation and Mitigation in the UK Food System , Sustainable Consumption Institute - University of Manchester.

Bows-Larkin, A. , McLachlan, C. , Mander, S. , Wood, R. , Roder, M. , Thornley, P. , Dawkins, E. , Gough, C. , O'Keefe, L. and Sharmina, M. (2014), "Importance of non-CO2 emissions in carbon management", Carbon Management, Vol. 5 No. 2, pp. 193-210. 
Bray, J. , Johns, N. and Kilburn, D. (2011), "An exploratory study into the factors impeding ethical consumption", Journal of Business Ethics , Vol. 98 No. 4, pp. 597-608

Buenstorf, G. and Cordes, C. (2008), "Can sustinable consumption be learned? A model of cultural evolution", Ecological Economics, Vol. 67 No. 4, pp. 646-657.

Calder, B.J. (1977), "Focus groups and the nature of qualitative marketing research", Journal of Marketing Research, Vol. 14 No. 3, pp. 353-364.

Carlsson-Kanyama, A. (1998), "Climate change and dietary choices - how can emissions of greenhouse gases from food consumption be reduced?", Food Policy, Vol. 23 Nos 3-4, pp. 277-293. [ Casimir, G. and Dutilh, C. (2003), "Sustainability: a gender studies perspective", International Journal of Consumer Studies, Vol. 27 No. 4, pp. 316-325.

Chambers, S. , Lobb, A. , Butler, L. , Harvey, K. and Bruce Traill, W. (2007), "Local, national and imported foods: a qualitative study", Appetite , Vol. 49 No. 1, pp. 208-213

Cholette, S. (2008), "Are locally-produced foods less energy-intensive than imports? Using

Carogoscope to compare energy usage for local and imported apples", Following from a grant from the Leonard Transportation Center at CSU, San Bernardino.

Cope, S. , Frewer, L.J. , Houghton, J. , Rowe, G. , Fischer, A.R.H. and de Jonge, J. (2010), “Consumer perceptions of best practice in food risk communication and management: implications for risk analysis policy", Food Policy, Vol. 35 No. 4, pp. 349-357

Daniels, S. , Glorieux, I. , Minnen, J. and van Tienoven, T.P. (2012), “More than preparing a meal? Concerning the meanings of home cooking", Appetite , Vol. 58 No. 3, pp. 1050-1056.

De Barcellos, M.D. , Kugler, J.O. , Grunert, K.G. , Van Wezemael, L., , Perez-Cueto, F.J.A. , Ueland, O. and Verbeke, W. (2010), "European consumers' acceptance of beef processing technologies: a focus group study", Innovative Food Science and Emerging Technologies, Vol. 11 No. 4, pp. 721-732.

De Boer, J. , Schosler, H. and Boersema, J.J. (2013), "Climate change and meat eating: an inconvenient couple?", Journal of Environmental Psychology, Vol. 33, pp. 1-8.

DEFRA (2010), "Food 2030", Department for Environment, Food and Rural Affairs, London. DEFRA (2011), "Family food 2010", Department for Environment, Food and Rural Affairs, London. Eating Better (2013), Briefing: Public Attitudes and Behaviors Research , Eating Better and YouGov. Edelman, P.D. , McFarland, D.C. , Mironov, V.A. and Matheny, J.G. (2005), "In Vitro-cultured meat production", Tissue Engineering , Vol. 11 Nos 5/6, pp. 659-662.

Evans, D. (2012), "Beyond the throwaway society: ordinary domestic practice and a sociological approach to household food waste", Sociology-the Journal of the British Sociological Association , Vol. 46 No. 1, pp. 41-56.

FAO (2006), "Livestock's long shadow", FAO. OpenURL UNIVERSITY OF MANCHESTER

FAO (2009), "The state of food and agriculture", FAO. OpenURL UNIVERSITY OF MANCHESTER Foresight (2011), The Future of Food and Farming , The Government Office for Science, London. Foster, C. , Green, K. , Bleda, M. , Dewick, P. , Evans, B. , Flynn, A. and Mylan, J. (2006), "Environmental impacts of food production and consumption: a report to the Department of Environment, Food and Rural Affairs (DEFRA)", Manchester Business School.

Friends of the Earth (2010), Who Benefits From Gm Crops? The Great Climate Change Swindle , Friends of the Earth, Amsterdam.

Garnett, T. (2008), "Cooking up a storm. Food, greenshouse gas emissions and our changing climate", FCRN

Garnett, T. (2011), "Where are the best opportunities for reducing greenhouse gas emissions in the food system (including the food chain)?", Food Policy, Vol. 36 No. S1, pp. S23-S32.

Gibbs, A. (1997), "Focus Groups”, Social Research Update, Vol. 19, Winter, pp. 1-6.

Grove-White, R. , Macnaghten, P. , Mayer, S. and Wynee, B. (1997), Uncertain World: Genetically Modified Organisms, Food and Public Attitudes in Britain, Centre for the Study of Environmental Change, Lancaster University, Lancaster.

Hargreaves, T. (2011), "Practice-ing behaviour change: applying social practice theory to proenvironmental behaviour change", Journal of Consumer Culture, Vol. 11 No. 1, pp. 79-99. 
Hartikainen, H. , Roininen, T. , Katajajuuri, J.-M. and Pulkkinen, H. (2014), "Finnish consumer perceptions of carbon footprints and carbon labelling of food products", Journal of Cleaner Production, Vol. 73, pp. 285-293.

Holm, L. and Møhl, M. (2000), "The role of meat in everyday food culture: an analysis of an interview study in Copenhagen", Appetite, No. 34, pp. 277-283.

Hoolohan, C. , Berners-Lee, M. , McKinstry-West, J. and Hewitt, C.N. (2013), "Mitigating the greenhouse gas emissions embodied in food through realistic consumer choices", Energy Policy , Vol. 63, pp. 1065-1074.

IPCC (2007), "Climate change 2007: synthesis report", contribution of working Groups I, II and III to the Fourth Assessment Report, Intergovernmental Panel on Climate Change, Geneva.

Irwin, A. and Wynne, B. (1996), Misunderstanding Science? The Public Reconstruction of Science and Technology , Cambridge University Press.

Jones, A. (2002), "An environmental assessment of food supply chains: a case study on dessert apples", Environmental Management, Vol. 30 No. 4, pp. 560-576.

Krueger, R. and Casey, M. (2000), Focus Groups: A Practical Guide for Applied Reseach , Sage, Thousand Oaks, CA.

Lorenzoni, I. , Nicholson-Cole, S. and Whittmarsh, L. (2007), "Barriers perceived to engaging with climate change among the UK public and their policy implications", Global Environmental Change , Vol. 17 Nos 3-4, pp. 445-459.

Mander, S. , Bows, A. , Gough, C. , Wood, R. , Thornley, P. , Mclachlan, C. , O'Keefe, L. , Roeder, M. and Dawkins, E. (2013), "How little or how much climate change? Facilitating stakeholder thinking on food system futures", 10th Conference European Ecological Economics Society, Lille, 17-21 June. Meat Free Monday Campaign (2013), "Meat Free Monday", available at:

www.meatfreemonday.com/about; (www.supportmfm.org) (accessed January 2013), new site available at: www.meatfreemonday.com/

Morgan, D. (1993), Successful Focus Groups: Advancing the State of the Art, SAGE.

Muhr, T. (1998), "Atlas/ti: The Knowledge Workbench, Short User's Manual, Atlas/ti, Berlin".

Murray, M. and Vickers, Z. (2009), "Consumer views of hunger and fullness. A qualitative approach", Appetite, Vol. 53 No. 2, pp. 174-182.

National Diet and Nutrition Survey (2012), "National diet and nutrition survey: headline results from Years 1, 2 and 3 combined (2008/9-2010/11)".

Nelson, C.H. (2001), "Risk perception, behavior, and consumer response to genetically modified organisms: toward understanding American and European public reaction", American Behavioral Scientist, Vol. 44 No. 8, pp. 1371-1388.

Owen, L. , Seaman, H. and Prince, S. (2007), Public understanding of Sustainable Consumption of FOOD: A Report to the Department for Environment, Food and Rural Affairs by Opinion Leader , London, DEFRA.

Pidgeon, N.F. , Poortinga, W. , Rowe, G. , Horlick-Jones, T. , Walls, J. and O’Riordan, T. (2005), “Using surveys in public participation processes for risk decision making: the case of the 2003 British GM nation? Public debate", Risk Perception, Vol. 25 No. 2, pp. 467-479.

Postill, J. (2010), "Introduction: theorising media and practice", in Brauchler, B. and Postill, J. (Eds), Theorising Media and Practice, Berghahn, Oxford and New York, NY, pp. 1-26.

Randles, S. and Warde, A. (2006), "Consumption: the view from theories of practice", in Green, K. and Randles, S. (Eds), Industrial Ecology and Spaces of Innovations, Edward Elgar, Cheltenham, pp. 220-237.

Röder, M. , Thornley, P. , Campbell, G. and Bows-Larkin, A. (2014), "Emissions associated with meeting the future global wheat demand: a case study of UK production under climate change constraints", Environmental Science \& Policy, Vol. 39, pp. 13-24.

Ronald, P. (2011), "Plant genetics, sustainable agriculture and global food security", Genetics, Vol. 188 No. 1, pp. 11-20. 
Schatzki, T.R. (2001), "Introduction: practice theory", in Schatzki, T.R. , Knorr, C.K. and Von Savigny, E. (Eds), The Practice Turn in Contemporary Theory, Routledge, London and New York, NY, pp. 1023.

Schatzki, T.R. (2002), The Site of the Social: A Philosophical Account of the Constitution of Social Life and Change, Pennsylvania State University Press, PA.

Shaw, A. (2002), "'It just goes against the grain'. Public understanding of genetically modified (GM) food in the UK", Public Understanding of Science, Vol. 11 No. 3, pp. 273-291.

Shove, E. and Pantzar, M. (2005), "Consumers, producers and practices: understanding teh invention and reinvention of Nordic walking", Journal of Consumer Culture, Vol. 5 No. 1, pp. 43-64.

Shove, E. and Warde, A. (2002), "Inconspicuous consumption: the sociology of consumption, lifestyles and the environment", in Dunlap, R. , Buttel, F. , Dickens, P. and Gijswijt, A.e. (Eds), Sociological Theory and the Environment: Classical Foundations, Contemporary Insights, Rowman and Littlefield, Lanham, MA, pp. 230-251.

Soil Association (2009), "Food futures: strategies for resilient food and farming", Soil Association. Speedy, A. (2003), "Global production and consumption of animla source foods", The American Society for Nutritional Sciences, Vol. 133 No. 11, pp. 40485-40535.

Stehfest, E. , Bouwman, L. , van Vurren, D.P. , den Elzen, M.G.J. , Eickhout, B. and Kabat, P. (2009), "Climate benefits of changing diet", Climate Change, Vol. 95 Nos 1-2, pp. 83-102

Stewart, D. , Shamdasani, P. and Rook, D. (2007), Focus Groups: Theory and Practice, SAGE, London. The Royal Society (2009), Reaping the Benefits; Science and The Sustainable Intensification of Global Agriculture , The Royal Society, London.

Therwell, D. (1999), "Using focus groups as a consumer research tool", Journal of Marketing Practice: Applied Marketing Science, Vol. 5 No. 4, pp. 102-105

Thorton, P.K. (2010), "Livestock production: recent trends, future prospects", Philosophical Transactions of the Royal Society, Vol. 365 No. 1554, pp. 2853-2867.

Tobler, C. , Visschers, V.H.M. and Siegrist, M. (2011), "Eating green. Consumers' willingness to adopt ecological food consumption behaviors", Appetite, Vol. 57 No. 3, pp. 674-682.

Tuomisto, H.L. and Teixeira de Mattos, M.J. (2011), "Environmental impact of cultured meat production", Environmental Science \& Technology , Vol. 45 No. 14, pp. 6117-6123. [CrossRef], Vanhonacker, F. , Van Loo, E.J. , Gellynck, X. and Verbeke, W. (2013), "Flemish consumer attitudes towards more sustainable food choices", Appetite, Vol. 62, pp. 7-16.

Warde, A. (2013), "What sort of a practice is eating?", in Shove, E. and Spurling, N. (Eds), Sustainable Practices: Social Theory and Climate Change, Routledge, Oxon, MD, pp. 10-23.

Webb, J. , Williams, A.G. , Hope, E. , Evans, D. and Moorhouse, E. (2013), "Do foods imported into the UK have a greater environmental impact than the same foods produced within the UK?", International Journal of Life Cycle Assessment, Vol. 18 No. 7, pp. 1325-1343.

Williams, A.G. , Audsley, E. and Sandars, D.L. (2006), Determining the Environmental Burdens and Resource Use in the Production of Agricultural and Horticultural Commodities , Crandfield University and Defra, Bedford.

Wood, F.R. , Dawkins, E.A. , Bows-Larkin, J. and Barrett, R. (2014), "Applying ImPACT: a modelling framework to explore the role of producers and consumers in reducing consumption emissions", Carbon Management, Vol. 5 No. 2, pp. 215-231.

WRAP (2011), "New estimates for household food and drink waste in the UK", WRAP. OpenURL UNIVERSITY OF MANCHESTER

\section{Further reading}

Warren, R. (2010), "The role of interactions in a world implementing adaptation and mitigation solutions to climate change", Philosophical Transactions of the Royal Society A , Vol. 369 No. 1934, pp. 217-241. 